\title{
Do acid-tolerant picocyanobacteria exist? A study of two strains isolated from humic lakes in Poland
}

\author{
Iwona Jasser • Anna Karnkowska-Ishikawa • \\ Ryszard J. Chróst
}

Received: 17 July 2012/Revised: 4 December 2012/Accepted: 8 December 2012/Published online: 1 January 2013

(C) The Author(s) 2012. This article is published with open access at Springerlink.com

\begin{abstract}
The occurrence of picocyanobacteria, the smallest cell-size fraction of cyanobacteria, in low-pH waters, is still poorly studied. In this study, we tested the hypothesis that picocyanobacteria found occasionally in low-pH environments are adapted to such water conditions. We isolated picocyanobacteria by means of the cytometric method from two humic lakes with $\mathrm{pH} \leq 5$. We obtained two strains belonging to two cosmopolitan phylogenetic clades of picocyanobacteria: Cyanobium gracile cluster and Subalpine cluster I. Experiments on filtered lake water from low-pH $(\leq 5)$ and slightly alkaline ( $\mathrm{pH}$ 8.2) lakes, and with an acidified cyanobacterium medium ( $\mathrm{pH} 4.5$ ) were conducted to test the growth of the isolated picocyanobacteria in various $\mathrm{pH}$ conditions. The experimental results of this study showed that some picocyanobacteria strains were acid
\end{abstract}

Handling editor: Luigi Naselli-Flores

Electronic supplementary material The online version of this article (doi:10.1007/s10750-012-1428-y) contains supplementary material, which is available to authorized users.

I. Jasser $(\bowtie) \cdot$ R. J. Chróst

Microbial Ecology Department, Institute of Botany,

Faculty of Biology, University of Warsaw, ul.

Miecznikowa 1, 02-096 Warsaw, Poland

e-mail: jasser.iwona@biol.uw.edu.pl

A. Karnkowska-Ishikawa

Department of Plant Systematics and Geography, Institute of Botany, Faculty of Biology, University of Warsaw, Al.

Ujazdowskie 4, 00-478 Warsaw, Poland tolerant, achieving higher growth rates and reaching higher maximum numbers in humic, naturally acidic waters rather than in alkaline waters. We show that despite a close phylogenetic relationship, strains of picocyanobacteria exhibit significant physiological and ecological diversity and that at least some picocyanobacteria have the evolutionary potential to cope with low $\mathrm{pH}$. Characterization of the genetic basis of acid tolerance in picocyanobacteria is important to understand how these microorganisms function in aquatic ecosystems and how their communities may respond to a changing environment.

Keywords 16S rDNA - Acidic environment . Acid-tolerant $\cdot$ Picocyanobacteria $\cdot$ Synechococcus

\section{Introduction}

Picocyanobacteria, the smallest cell-size fraction of cyanobacteria with a diameter of $<2 \mu \mathrm{m}$, represent the Earth's most numerous phototrophic organisms. Together with eukaryotic algae, they form autotrophic picoplankton: the smallest fraction of phytoplankton.

Picocyanobacteria comprise cyanobacteria from the genera Synechococcus and Prochlorococcus in the oceans, while in freshwaters, they are represented mostly by the former as well as Cyanobium (Partensky et al., 1999; Callieri, 2007). Picocyanobacteria contribute substantially to overall primary production (Bell \& Kalff, 2001), usually dominate in nutrient- 
poor environments (Callieri, 2007), and traditionally are not considered to occur in acidic waters, with pH 6 as the apparent threshold level (Søndergaard, 1991; Stockner \& Shortreed, 1991). Thanks to their small size, high surface-to-volume ratio and a small diffusion boundary layer around a single cell, picocyanobacteria have an advantage in the acquisition of resources and their efficient use compared with bigger phytoplankton. This is the reason that they can thrive in oligotrophic environments. Advantageous as this may seem, the same features may occasionally work against picocyanobacteria. This is because their smallsize cells are prone to leakage of substances due to osmotic forces. Nutrients from the cells can leak out, while unwanted substances, such as $\mathrm{H}^{+}, \mathrm{Na}^{+}$, and $\mathrm{Ca}^{+}$, can enter them (Raven, 1998; Irwin et al., 2006). In this respect, it seems plausible that picocyanobacteria may be more vulnerable than larger cells to a low $\mathrm{pH}$ because it may be harder for the former to maintain their intracellular $\mathrm{pH}$. Thus, the absence or low numbers of picocyanobacteria in low-pH waters has not been a surprise for limnologists. Meanwhile, there have been some reports suggesting that picocyanobacteria may actually exist in waters of $\mathrm{pH} \leq 5$ (Steinberg et al., 1998; Jasser \& Arvola, 2003), but in the face of scarce evidence, it has not been firmly accepted as part of picocyanobacteria ecology.

In recent years, studies on picocyanobacteria diversity and phylogeny have been rapidly increasing in the backdrop of extensive isolation of strains and analysis of in situ DNA samples collected from various marine and freshwater environments, allowing for a new look at this issue. Molecular analysis of $16 \mathrm{~S}$ rRNA genes has resulted in the division of picocyanobacteria into several marine and freshwater clusters (Herdman et al., 2001). Among them, cosmopolitan and unique clusters and sequences have been identified (Crosbie et al., 2003a; Haverkamp et al., 2008; Sánchez-Baracaldo et al., 2008; Jasser et al., 2011), although the ecophysiological differences between strains belonging to various clusters often remain uncharacterized.

The aims of this study were to (i) isolate picocyanobacteria from acidic, humic lakes of $\mathrm{pH} \leq 5$ in which they have been previously detected; (ii) determine the phylogenetic position of isolated strains; (iii) compare the growth of these strains in this acidic environment and in slightly alkaline waters; and (iv) verify whether closely related strains isolated from neutral/slightly alkaline waters possess similar adaptations.

\section{Materials and methods}

Study site and sampling

The studied lakes belong to the Mazurian Lake District in North-Eastern Poland $\left(54^{\circ} \mathrm{N}\right.$ and $\left.22^{\circ} \mathrm{E}\right)$. The Lake Kruczy Staw $\left(53^{\circ} 40^{\prime} \mathrm{N}, 21^{\circ} 24^{\prime} \mathrm{E}\right)$ is an oligo-mesohumic, moderately productive lake. The Lake Smolak Duży $\left(53^{\circ} 43^{\prime} \mathrm{N}\right.$ and $\left.21^{\circ} 36^{\prime} \mathrm{E}\right)$, is a shallow, productive,

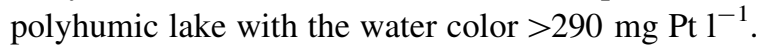
Both lakes are acidic, with the inter-annual variation of $\mathrm{pH}$ between 4.6 and 5.5 in Kruczy Staw, and between 4.7 and 5 in Smolak Duży (Supplementary Files 1 and 2).

To analyze the abundance of picocyanobacteria, samples were collected monthly from April till October 2005, and three times in 2006: in the spring and early summer. Integrated samples were taken with a 2-1 Limnos sampler from the euphotic zone during the mixing time and from the epilimnion, during the stratification period, of Lake Kruczy Staw and from the surface to 2.5-m depth in Lake Smolak Duży. The samples were fixed with pre-filtered formaldehyde to a final concentration of $1 \%$ (Malinsky-Rushansky \& Berman, 1991) and stored in darkness at $4^{\circ} \mathrm{C}$. The picocyanobacteria were identified and enumerated under a fluorescent microscope (NIKON Eclipse, E400, Tokyo, Japan) with green CY3 (HYQ) and blue B-2A filters (Jasser et al., 2010).

\section{Strain isolation and cultivation}

The isolation of picocyanobacteria from the studied lakes was performed in July 2008, when pH in Lake Kruczy Staw was 4.6, and in Lake Smolak Duży it was 4.9. It was done by flow cytometry using a modified method of Crosbie et al. (2003b), (Jasser et al., 2010). Sorting of natural lake water samples was performed by means of a FACSCalibur (Becton-Dickinson, Franklin Lakes, NJ USA) flow cytometer, equipped with a 488-nm laser. The sorter was calibrated using the following reference strains: Synechococcus rubescens (SAG 3.81) for phycoerythrin (PE)-rich cells, and PCC 6307 and PCC 7998 for phycocyanin (PC)-rich 
cells. The sorting gates were targeting PE-rich and PCrich picocyanobacteria, and the samples were sorted twice, targeting first the chosen type of PE-rich cells and later the PC-rich cells.

Before sorting, natural lake water samples from both humic lakes were filtered through $2.0-\mu \mathrm{m}$-pore size filters. The culture enrichment step proposed by Crosbie et al. (2003b) was omitted in accordance with results of the previous isolation of strains from Mazurian lakes (Jasser et al., 2010). Except for the absence of culture enrichment, the isolation procedure was exactly the same as the one described by Jasser et al. (2010).

The isolation was performed in the WC medium (nutrient-poor growth medium) (Guillard \& Lorenzen, 1972) and BG11 medium (nutrient-rich cyanobacteria growth medium) (Stanier et al., 1971). Similar to the method of isolations adopted in the previous year (Jasser et al., 2010), we obtained strains only in the WC medium that is nutrient-poor. However, for the longterm cultivation, we transferred the strains to the BG11 medium; thus, the cells used in subsequent experiments were cultivated for many generations in BG11.

After executing isolation, all the cultures were propagated in a plant growth chamber at a constant temperature of $18^{\circ} \mathrm{C}$ and at $14: 10$-h day:night cycle with cool white light illumination at $16 \mu \mathrm{mol}$ photons $\mathrm{m}^{-2} \mathrm{~s}^{-1}$, provided by fluorescent tubes $(4000 \mathrm{~K}$, OSRAM Lumilux, Munich, Germany).

DNA isolation, amplification, and sequencing

Isolation of total DNA, amplification of the 16S rDNA region, and purification and sequencing of PCR products were all performed by standard methods, as described previously (Jasser et al., 2011).

Sequence accession numbers, alignment, and phylogenetic analysis

The two new sequences generated in the present study were submitted to the GenBank database and were assigned the following accession numbers: JQ030885for strain KS0708; and JQ030886 - for strain SM0708. The accession numbers for all the 16S rDNA sequences reported here and used in the phylogenetic analysis are shown in Supplementary File 3. Sequence alignment, obtained using ClustalX 1.83 (Thompson et al., 1997) with default options, was manually checked and edited using Genetic Data Environment (GDE 2.4) software (Smith et al., 1994). Regions that could not be unambiguously aligned were excluded from the analysis. 16S rDNA sequences from the two newly isolated strains and closely related sequences obtained from GenBank were used for the phylogenetic analysis. Sequences belonging to well-known clades as well as recent accessions obtained from various environments were chosen. The main selection criteria were a sequence length of c.a. 1400 characters and a clear description of the environment from which the samples were derived. In total, a 16S rDNA dataset of 1,347 characters in the alignment of 208 sequences was generated.

Phylogenetic trees were constructed using Maximum-likelihood methods (ML) implemented in PhyML-aLRT 1.1 (Guindon \& Gascuel, 2003), using an input tree generated by BIONJ with a general-timereversible model (Rodríguez et al., 1990) of nucleotide substitution incorporating invariable sites and a discrete gamma distribution $(\mathrm{GTR}+\mathrm{I}+\Gamma)$. The proportion of invariable sites, discrete gamma distribution, and base frequencies of the model were estimated from the dataset. Statistical support for phylogenetic grouping was assessed by approximate likelihood-ratio tests based on a Shimodaira-Hasegawa-like procedure (SHaLRT) (Anisimova \& Gascuel, 2006).

The sequences from strains PCC 6301 and PCC 7942 were used to root the trees (Ernst et al., 1995; Haverkamp et al., 2008), which were drawn with FigTree v1.3.1 (available at http://tree.bio.ed.ac.uk/software).

\section{Experimental design}

Four strains were used in the experiments: two isolated in the present study from the humic, low-pH lakes Smolak Duży and Kruczy Staw and two others obtained in 2007 from eutrophic, slightly alkaline lakes located in the same area of the Mazurian Lake District, Poland (Jasser et al., 2010). Basic data concerning these strains, the lakes from which they were isolated and from which water was taken for the experiments, are summarized in Supplementary File 2.

In the course of the study, three experiments were performed: two with lake water from the lakes of isolation (filtered through $\mathrm{GF} / \mathrm{F}$ filters), and one experiment with an acidified BG11 medium. The experiments with the lake water included experiment 
I-for acidic strains, which was performed in July 2010; and experiment II-for alkaline strains, performed at the end of May 2011. For experiment III with acidified BG11, which was performed in October 2011, all four strains were used. Before starting the experiments; cultures of all four strains were examined under a fluorescence microscope to enumerate them. The cultures were then centrifuged at $2600 \times g$ for $20 \mathrm{~min}$ to remove the growth medium. The cells were then suspended in different media representing the experimental treatments. The cultures were grown in 50-ml sterile glass vessels, swirled twice a day.

In the experiments I and II, three treatments were used (Table 1):

(i) Filtered water from the lakes from which the given strain was isolated: acidic water $(\mathrm{pH} 4.9)$ from Kruczy Staw for strain KS0708, acidic water ( $\mathrm{pH}$ 4.7) from Smolak Duży for SM0708, slightly alkaline ( $\mathrm{pH}$ 8.3) water from Lake Mikołajskie for MI0507B and slightly alkaline ( $\mathrm{pH}$ 8.2) water from Lake Bełdany for BE0807K;

(ii) Filtered water from the eutrophic, slightly alkaline ( $\mathrm{pH}$ 8.3) Lake Mikołajskie in the case of acidic strains in the experiment I. In the experiment II, filtered water from acidic lakes was used for alkaline strains; and

(iii) The BG11 medium ( $\mathrm{pH} 8.2$ ), which served as an optimal growth control because all strains had been grown in this medium for many generations. The strains obtained from low-pH lakes were cultured for about 500 generations before experiment I, and those from alkaline lakes for about 800 generations before experiment II.

In the experiment II, water from Lake Smolak Duży (pH 4.9) was used for strain BE0807K (PC), while water from Lake Kruczy Staw ( $\mathrm{pH}$ 5.0) was used for strain MI0507B (PE), (Supplementary File 2). The underwater light climate in Lake Smolak Duży, owing to the high concentration of humic substances and the predominance of red light, was more suitable for PC cells, whereas Lake Kruczy Staw contains less humic organic matter, and so the underwater light climate was considered to be more favorable for PE cells (Vörös et al., 1998). In every experiment, three replicates of each treatment were prepared. The experiments with lake water were performed at the Mikołajki field station in the Mazurian Lake District, Poland, in the plant growth chamber under continuous light $\left(16 \mu \mathrm{mol}\right.$ photons $\left.\mathrm{m}^{-2} \mathrm{~s}^{-1}\right)$ at a constant temperature: $20^{\circ} \mathrm{C}$ in experiment $\mathrm{I}$, and $18^{\circ} \mathrm{C}$ in experiment II. The initial abundance of picocyanobacteria in all treatments within each experiment was comparable. Starting at $8 \mathrm{pm}$, the experimental cultures were sampled every $12 \mathrm{~h}$ for 4 days. The cells were enumerated using a fluorescence microscope (NIKON Eclipse, E400, Tokyo, Japan), growth curves were plotted for each strain in each treatment, and mean (and $\mu_{\text {mean }}$ ) maximum specific growth rates $\left(\mu_{\max }\right)$ were determined from the slope of linear regressions of the ln-transformed cell counts during the whole and exponential growth phases, respectively (Chróst et al., 1988). In addition, we indicated the length of the whole growth phase including the lag phase. Statistica package v. 9 (StatSoft Inc., Tulsa, OK, USA) was used to test for a potential difference in the population density of cyanobacteria in eight time periods over $84 \mathrm{~h}$ of experiment in $2 \times 2$ factorial ANOVA with repeated measures (RM-ANOVA) in two independent tests. Each analysis investigated differences in the population density of two pairs of cyanobacteria strains originating either from the acidic or alkaline waters.

In the experiment III, we checked if all four isolated strains were able to grow in the acidified BG11 medium.

Table 1 Treatments used in the experiments with filtered lake water

\begin{tabular}{|c|c|c|c|c|c|}
\hline \multicolumn{3}{|l|}{ Experiment I } & \multicolumn{3}{|l|}{ Experiment II } \\
\hline \multicolumn{3}{|c|}{ Acidic strain KS0708 } & \multicolumn{3}{|c|}{ Alkaline strain MI0507B } \\
\hline Lake water KS & Lake water MI & BG11 & Lake water MI & Lake water KS & BG11 \\
\hline $\mathrm{pH} 4.9$ & pH 8.3 & pH 8.2 & pH 8.3 & $\mathrm{pH} 5$ & $\mathrm{pH} 8.2$ \\
\hline \multicolumn{3}{|c|}{ Acidic strain SM0708 } & \multicolumn{3}{|c|}{ Alkaline strain BE0807K } \\
\hline Lake water SM & Lake water MI & BG11 & Lake water BE & Lake water SM & BG11 \\
\hline $\mathrm{pH} 4.7$ & $\mathrm{pH} 8.3$ & $\mathrm{pH} 8.2$ & $\mathrm{pH} 8.2$ & pH 5 & $\mathrm{pH} 8.2$ \\
\hline
\end{tabular}


The cultures of strains previously used in experiments I and II were prepared in the same way as before: the cells were enumerated; the cultures were centrifuged to remove the old, slightly alkaline medium ( $\mathrm{pH} 8.2)$; and re-suspended in BG11 acidified with $0.1 \mathrm{~N} \mathrm{HCL}$ to $\mathrm{pH}$ 4.5; and enumerated again. The experimental cultures were grown in 50-ml sterile glass vessels in a plant growth chamber at $18^{\circ} \mathrm{C}$ and at $14: 10$-h day:night light cycle. Experiment III was performed in the laboratory in Warsaw and lasted 14 days.

\section{Results}

Picocyanobacteria were observed in lakes-Kruczy Staw and Smolak Duży, two moderately acidic, humic lakes in the Mazurian Lake District, Poland. The numbers of picocyanobacterial cells in the studied lakes varied from not detectable or low numbers in Lake Kruczy Staw to considerably high in very humic Lake Smolak Duży, where they reached $7 * 10^{4}$ cells $\mathrm{ml}^{-1}$ in 2005 and $8 * 10^{4}$ cells $\mathrm{ml}^{-1}$ in 2006 (Supplementary File 1). On average, cyanobacteria accounted for $22 \%$ of autotrophic picoplankton numbers and about $6 \%$ of biomass in this polyhumic lake in 2005.

In 2008, we isolated a phycocyanin (PC)-rich strain (SM0708) from Lake Smolak Duży and a phycoerythrin (PE)-rich strain (KS0708) from Lake Kruczy Staw. Cells of the isolated PC-rich SM0708 and PE-rich KS0708 strains have an oval shape. Both strains divide in one plain. However, the PC-rich strain divides by pinching, while the PE-rich does by cleavage.

On the basis of the 16S rDNA analysis, the phylogenetic position of these strains was determined (Fig. 1; Supplementary Files 3, 4). Both strains belong to wellknown cosmopolitan clades: the PC strain to Group A (Cyanobium gracile cluster), and the PE strain to Group B (Subalpine cluster I) (Crosbie et al., 2003a). Both clades fall within cluster 5 , which consists of marine and freshwater strains (Herdman et al., 2001). Within these clades, the strains obtained in the present study are closely related to the strains isolated from various environments. In the case of KS0708, the strain is closely related to strains isolated from Lake Maggiore (LM94), Lake Majcz (MA0607), Lake Zurich (SAG3.81), and Lake Xinxinhai (XZXXH51). SM0708 is related to strains from Lake Balaton (ACT9802), the Baltic Sea (B9801), Lake Wisconsin (PCC6307), or even a stream in California (PCC6904; Supplementary File 3).
We performed the experiments with the newly isolated strains and two strains belonging to the same phylogenetic groups but isolated from neighboring, slightly alkaline lakes (Jasser et al., 2011). The strains isolated from humic, acidic lakes were able to grow better in the low-pH lake water (Fig. 2a, b), achieving higher cell numbers than in the slightly alkaline lake water. In addition, their maximum specific growth rates $\left(\mu_{\max }\right)$ in the acidic lake water were much higher than those in alkaline water and in the BG11 medium. The overall growth phases (including lag and stationary phases) were visibly longer in the humic lake water than in those alkaline water (Table 2). The statistical analysis showed a significant effect of the water type with different $\mathrm{pH}$ values (RM-ANOVA, $F_{1,56}=102$; $P=0.000008$ ) and times (RM-ANOVA, $F_{7,56}=28$; $P=0.000000)$ on the population density of acidic strains in the course of experiment I.

In the experiment II, we determined whether other strains-belonging to the same phylogenetic groups, but isolated from slightly alkaline lakes_exhibit a similar ability to grow in naturally acidic, humic lake water. A PC strain (BE0807K) from Lake Bełdany, belonging to phylogroup A, and a PE strain (MI0507B) from Lake Mikołajskie assigned to Group B, performed much worse in lake water of $\mathrm{pH} \leq 5$ (Fig. $2 \mathrm{c}, \mathrm{d}$ ). Their $\mu_{\max }$ and maximum numbers in the low-pH water were, for the PC strain and for PE strain, substantially lower than the corresponding values in alkaline water and the BG11 medium. Also, the length of the overall growth phase was much shorter in the acidic water than in alkaline water or BG11 medium (Table 2). The statistical analysis also showed a significant impact of the water type with different $\mathrm{pH}$ values (RM-ANOVA, $\left.F_{1,56}=117 ; P=0.000005\right)$ and times (RM-ANOVA, $\left.F_{7,56}=37 ; P=0.000000\right)$ on the population density of alkaline strains in the course of the experiment. Moreover, the analysis revealed a significant difference in population density between two alkaline strains (RM-ANOVA, $F_{1,56}=55 ; P=0.00007$ ), unlike in the case of an acidic pair (RM-ANOVA, $F_{1,56}=2$; $P=0.17)$. In most of the treatments in both the experiments, the mean growth rate $\left(\mu_{\text {mean }}\right)$ calculated for the whole growth period also exhibited a similar pattern as the $\mu_{\max }$ (Table 2).

In the experiment III, we checked if the studied picocyanobacteria strains were able to grow in a BG11 medium acidified to $\mathrm{pH} 4.5$ (Fig. 3). The strains isolated from acidic lakes (KS0708 and SM0708) 


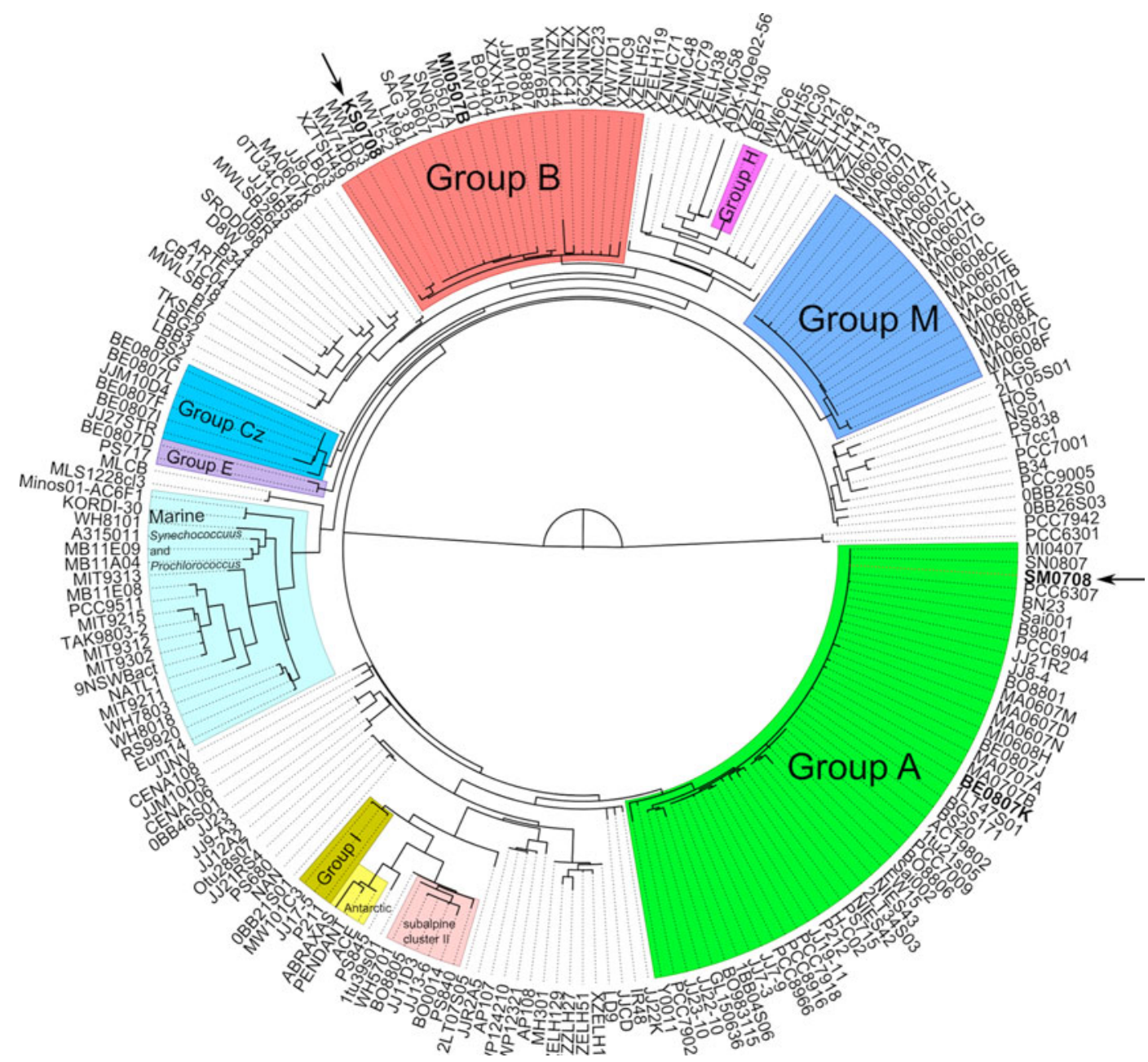

Fig. 1 Phylogenetic relationships of picocyanobacteria. Phylogenetic analysis was performed using maximum-likelihood methods as implemented in PhyML-aLRT, based on 16S rDNA nucleotide sequences. Sequences determined in the experiments

performed better in the low-pH medium than the strains isolated from slightly alkaline lakes (MI0507B and BE0807K). The first two strains increased their numbers slightly, while the two alkaline strains dropped down within the first 5 days and remained in low numbers until the end of the experiment (Fig. 3).

\section{Discussion}

This study demonstrates that picocyanobacteria are able to grow in humic, naturally acidic environments and confirmed earlier incidental reports of their presence in low-pH waters (Steinberg et al., 1998; are given in bold font. Arrows indicate acidic strains. GenBank accession numbers are shown in Supplementary File 3, and branch support values (approximate likelihood-ratio test probabilities) associated with nodes are shown in Supplementary File 4

Jasser \& Arvola, 2003). Owing to their seemingly occasional occurrence in varying numbers even in the same lake (Jasser et al., 2009 and present study), the ecological importance of picocyanobacteria in acidic waters, though sometimes significant as reported by Steinberg et al. (1998) and Jasser \& Arvola (2003), is still uncertain and should be further studied. Nonetheless, this study provides evidence that picocyanobacteria isolated from low-pH, humic lakes seem adapted to such an environment and even after about 500 generations in laboratory conditions (over 2 years), this adaptation is evident in the better growth in such waters than in alkaline lake waters. We are aware that the low $\mathrm{pH}$ is not the only factor influencing 

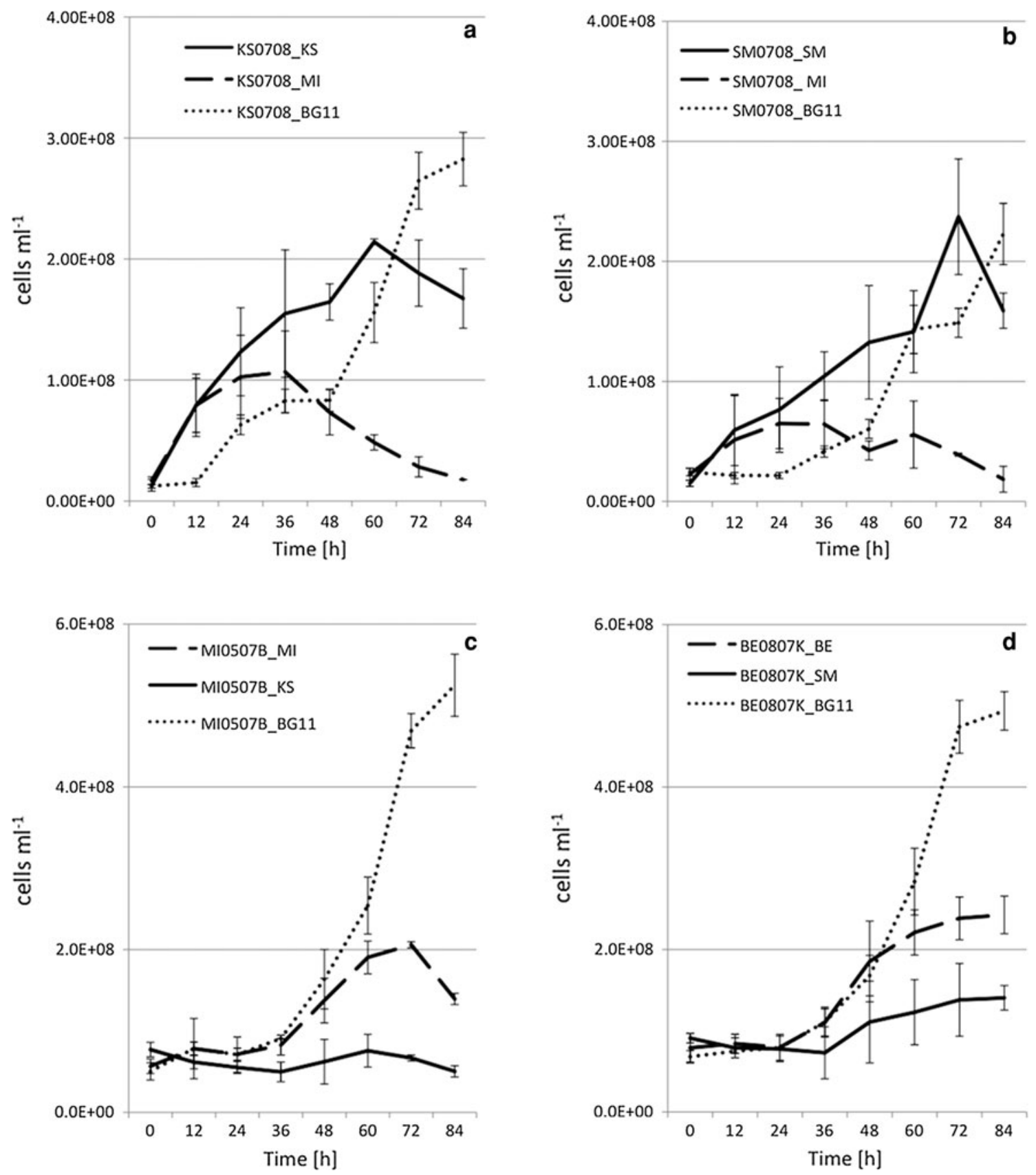

Fig. 2 Growth curves for acidic picocyanobacteria strains in experiment I (a, b); and alkaline strains in experiment II $(\mathbf{c}, \mathbf{d})$. KS0708_KS, SM0708_SM, MI0507B_MI, and BE0807K_BEstrains cultivated in water from the lake from which each was isolated; KS0708_MI and SM0708_MI-acidic strains cultivated in alkaline lake water; MI0507B_KS and BE0807K_SM-

alkaline strains cultivated in acidic lake water; KS0708_BG11, SM0708_BG11, MI0507B_BG11, and BE0807K_BG11strains grown in BG11 medium. Solid line, strains cultivated in acidic lake water. Dashed line, strains cultivated in alkaline lake water. Dotted line, strains cultivated in BG11 medium

the growth of picocyanobacteria in humic, acidic lakes but that other factors, such as presence of humic substances, light availability, and the concentration

and accessibility of nutrients, also could enhance the growth of acid lake-derived strains and limit growth of alkaline lake-derived strains in our experiments. 
Table 2 Mean and maximum growth rates and standard deviation calculated as regression analysis for whole growth phase, as well as the length of overall growth phase including lag and stationary phases growth phase and exponential

\begin{tabular}{lllllll}
\hline & $\begin{array}{l}\text { Mean growth } \\
\text { rate } \mu_{\text {mean }} \\
\left(\mathrm{d}^{-1}\right)\end{array}$ & $\begin{array}{l} \pm D \\
\text { Experiment I }\end{array}$ & $\begin{array}{l}\text { Max growth } \\
\text { rate } \mu_{\max } \\
\left(\mathrm{d}^{-1}\right)\end{array}$ & $\begin{array}{l} \pm \mathrm{SD} \\
\begin{array}{l}\text { Mean/ } \\
\text { Max } \\
\text { growth } \\
\text { rate }\end{array}\end{array}$ & $\begin{array}{l}\text { Length of } \\
\text { overall growth } \\
\text { phase (h) }\end{array}$ \\
KS0708_KS & 0.935 & 0.013 & 2.247 & 0.021 & 0.416 & 60 \\
KS0708_MI & 1.162 & 0.022 & 1.796 & 0.042 & 0.647 & 36 \\
KS0708_BG11 & 0.925 & 0.008 & 1.162 & 0.008 & 0.796 & 84 \\
SM0708_SM & 0.749 & 0.005 & 1.625 & 0.014 & 0.461 & 72 \\
SM0708_MI & 0.669 & 0.011 & 1.050 & 0.011 & 0.637 & 36 \\
SM0708_BG11 & 0.891 & 0.009 & 1.019 & 0.009 & 0.874 & 72 \\
Experiment II & & 0.002 & 0.422 & 0.005 & 0.564 & 24 \\
MI0507B_KS & 0.238 & 0.009 & 0.611 & 0.003 & 0.723 & 72 \\
MI0507B_MI & 0.442 & 0.010 & 0.925 & 0.007 & 0.770 & 84 \\
MI0507B_BG11 & 0.712 & 0.005 & 0.403 & 0.006 & 0.608 & 48 \\
BE0807K_SM & 0.245 & 0.011 & 0.581 & 0.003 & 0.688 & 84 \\
BE0807K_MI & 0.400 & 0.007 & 0.976 & 0.007 & 0.661 & 84 \\
BE0807K_BG11 & 0.645 & & & & & \\
\hline
\end{tabular}

Fig. 3 Changes of picocyanobacteria numbers of acid lake-derived and alkaline lake-derived strains cultivated in a BG11 acidified to $\mathrm{pH} 4.5$

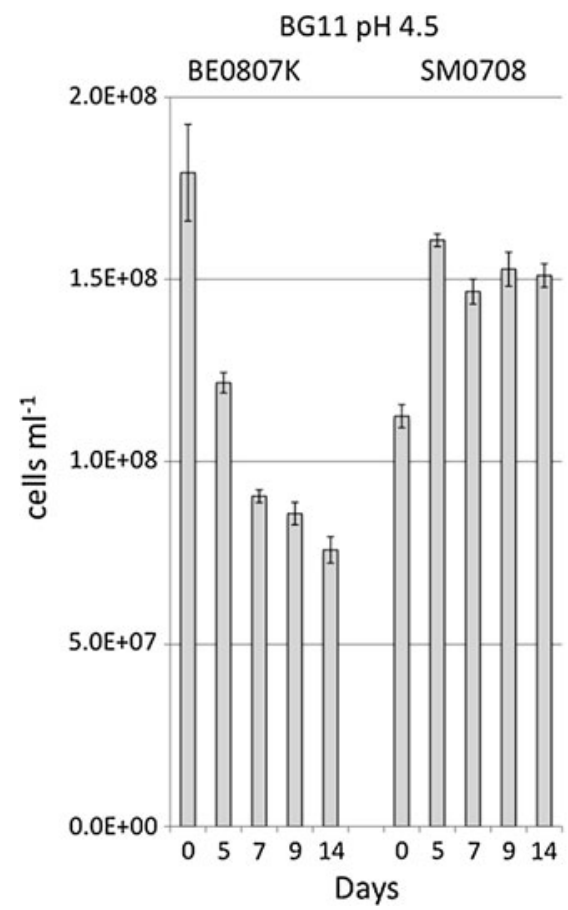

However, there is no doubt that the low $\mathrm{pH}$ of the humic lakes water did not prevent the acid lakederived strains from growing, supporting the idea that they are adapted to low $\mathrm{pH}$. Further, as it was shown in the experiment with the acidified BG11, when other growth conditions were known and similar for all strains cultivated in the laboratory, the acid lake- derived strains coped better with a low $\mathrm{pH}$ of the medium compared to the strains isolated from neutral/ slightly alkaline lakes.

The present study demonstrated that some picocyanobacteria, especially when grown in naturally acidic, humic lake water, can perform better in such acidic water than in alkaline lake waters, which had 
been considered more suitable for cyanobacteria (Brock, 1973) and particularly picocyanobacteria (Callieri, 2007). This complements earlier findings concerning acid-stress response, which revealed several mechanisms enabling various microorganisms to survive under low $\mathrm{pH}$ in laboratory conditions (Kallas \& Castenholz, 1982; Foster \& Hall, 1991; Huang et al., 2002; Kurian et al., 2006). Among them are analyses of Synechocystis 6308, a strain isolated from Lake Wisconsin, which turned out to be able to respond to and survive the acid stress by increasing the $\mathrm{pH}$ in culture (Huang et al., 2002). Those authors did not ascertain if the acid-stress response they described was intrinsic to the studied organisms or was acquired in the laboratory conditions.

Our results suggest that the ability of two strains isolated from acidic lakes to cope with low $\mathrm{pH}$ is intrinsic to these organisms. The study demonstrated further that different strains within the cosmopolitan clades A and B, which are closely related to acid lakederived isolates obtained by us, were isolated from nearby lakes and kept in laboratory in similar conditions, do not share this ability. This is a result different from that in the case of Chlamydomonas acidophila, a green alga often abundant in acidic freshwaters, which clearly forms a separate, well supported clade within genus Chlamydomonas (Gerloff-Elias et al., 2005). The affiliation of the acid lake-derived picocyanobacteria strains to cosmopolitan groups A and B suggests that the tolerance to low $\mathrm{pH}$ is not connected with the phylogenetic position, and thus implies the possibility that strains in other clades, including those from marine environments, could show a similar variance.

Whether the origin of this adaptation to acidic environments represents a phenotypic plasticity or reflects genetic differences between strains is yet to be determined. At the moment, though, it seems to be genetically fixed, a notion supported by differences in the reaction of studied strains to an abrupt change of $\mathrm{pH}$. Results of the present study may have broader implications than just for humic, acidic lakes because a genetic diversity of picocyanobacteria may cause shifts in communities in other changing environments, possibly including marine ones. Interestingly, parallel to the decline in the phytoplankton biomass due to the global warming (Behrenfeld et al., 2006), picocyanobacteria numbers are increasing in the oceans, suggesting their potentially greater role in primary production and carbon sequestration (Agawin et al.,
2000; Richardson \& Jackson, 2007; Morán et al., 2010). As global warming is accompanied by the acidification of the oceans (Boyd, 2011), this may influence growth optima for various strains of picocyanobacteria even if the scale of ocean $\mathrm{pH}$ changes is minor compared to significant differences in our studies. Thus, it would be interesting to establish how picocyanobacteria communities respond to changing conditions not only in terms of rising $\mathrm{CO}_{2}$ concentrations (Lu et al., 2006) but also a pH decrease. Therefore, more in-depth data on the genetic basis of acid tolerance in picocyanobacteria are required.

Acknowledgments This study was supported by grants from the Polish Ministry of Science and Higher Education (N304 $01531 / 0535$ and N304 102240). The authors are grateful to John Gittins for his critical comments and correcting the language, which helped in improving the manuscript; Tomasz Kaliński and Elsi Kauppinen for chemical analyses; and Aleksandra Bukowska and Katarzyna Jakubiec for maintaining our cyanobacteria culture collection as well as Mirosław Ślusarczyk for help with statistical analyses. The authors would also like to thank the two anonymous reviewers for their detailed and constructive comments, which greatly improved the quality of this article.

Open Access This article is distributed under the terms of the Creative Commons Attribution License which permits any use, distribution, and reproduction in any medium, provided the original author(s) and the source are credited.

\section{References}

Agawin, N. S. R., C. M. Duarte \& S. Agust, 2000. Nutrient and temperature control of the contribution of picoplankton to phytoplankton biomass and production. Limnology and Oceanography 45: 591-600.

Anisimova, M. \& O. Gascuel, 2006. Approximate likelihoodratio test for branches: a fast, accurate, and powerful alternative. Systematic Biology 55: 539-552.

Behrenfeld, M. J., R. T. O’Malley, D. A. Siegel, C. R. McClain, J. L. Sarmiento, G. C. Feldman, A. J. Milligan, P. G. Falkowski, R. M. Letelier \& E. S. Boss, 2006. Climate-driven trends in contemporary ocean productivity. Nature 444 : 752-755.

Bell, T. \& J. Kalff, 2001. The contribution of picophytoplankton in marine and freshwater communities of different trophic status and depth. Limnology and Oceanography 46: 1243-1248.

Boyd, P. W., 2011. Beyond ocean acidification. Nature Geoscience 4: 273-274.

Brock, T. D., 1973. Lower pH limit for the existence of bluegreen algae: evolutionary and ecological implications. Science 179: 480-483.

Callieri, C., 2007. Picophytoplankton in aquatic ecosystems: the importance of small-sized phototrophs. Freshwater Reviews 1: 1-28. 
Chróst, R. J., J. Overbeck \& R. Wcisło, 1988. Evaluation of the $\left[{ }^{3} \mathrm{H}\right]$ thymidine method for estimating bacterial growth rates and production in lake water: re-examination and methodological comments. Acta Microbiologica Polonica 37: 95-112.

Crosbie, N. D., M. Pöckl \& T. Weisse, 2003a. Dispersal and phylogenetic diversity of nonmarine picocyanobacteria, inferred from $16 \mathrm{~S}$ rRNA gene and $c p c \mathrm{BA}$ intergenic spacer sequence analyses. Applied and Environmental Microbiology 69: 5716-5721.

Crosbie, N. D., M. Pöckl \& T. Weisse, 2003b. Rapid establishment of clonal isolates of freshwater autotrophic picoplankton by single-cell and single-colony sorting. Journal of Microbiological Methods 55: 361-370.

Ernst, A., P. Marschall \& C. Postius, 1995. Genetic diversity among Synechococcus spp. (cyanobacteria) isolated from the pelagial of Lake Constance. FEMS Microbiology Ecology 17: 197-204.

Foster, J. W. \& H. K. Hall, 1991. Inducible pH homeostasis and the acid tolerance response of Salmonella typhimurium. Journal of Bacteriology 173: 5129-5135.

Gerloff-Elias, A., E. Spijkerman \& T. Pröschold, 2005. Effect of external $\mathrm{pH}$ on the growth, photosynthesis and photosynthetic electron transport of Chlamydomonas acidophila Negoro, isolated from an extremely acidic lake ( $\mathrm{pH} 2.6)$. Plant, Cell and Environment 28: 1218-1229.

Guillard, R. R. L. \& C. J. Lorenzen, 1972. Yellow-green algae with chlorophyllide c. Journal of Phycology 8: 10-14.

Guindon, S. \& O. Gascuel, 2003. A simple, fast and accurate algorithm to estimate large phylogenies by maximum likelihood. Systematic Biology 52: 696-704.

Haverkamp, T., S. G. Acinas \& M. Doeleman, 2008. Diversity and phylogeny of Baltic Sea picocyanobacteria inferred from their ITS and phycobiliprotein operons. Environmental Microbiology 10: 174-188.

Herdman, M., R. W. Castenholz, J. B. Waterbury \& R. Rippka, 2001. Form-genus XIII. Synechococcus. In Boone, D. R. \& R. W. Castenholz (eds.), Bergey's manual of systematic bacteriology. Springer, New York: 508-512.

Huang, J. J., N. H. Kolodny, J. T. Redfearn \& M. M. Allen, 2002. The acid stress response of the cyanobacterium Synechocystis sp. strain PCC 6308. Archives of Microbiology 177: 486-493.

Irwin, A. J., Z. V. Finkel, O. M. E. Schofield \& P. G. Falkowski, 2006. Scaling-up from nutrient physiology to the sizestructure of phytoplankton communities. Journal of Plankton Research 28: 459-471.

Jasser, I. \& L. Arvola, 2003. Potential effects of abiotic factors on the abundance of autotrophic picoplankton in four boreal lakes. Journal of Plankton Research 25: 873-883.

Jasser, I., I. Kostrzewska-Szlakowska, J. Ejsmond-Karabin, K. Kalinowska \& T. Węgleńska, 2009. Autotrophic versus heterotrophic production and components of trophic chain in humic lakes: the role of microbial communities. Polish Journal of Ecology 57: 423-439.

Jasser, I., A. Karnkowska-Ishikawa, E. Kozłowska, A. Królicka \& M. Łukomska-Kowalczyk, 2010. Isolation of picocyanobacteria from Great Mazurian Lake System - comparison of two methods. Polish Journal of Microbiology 59: $21-31$.

Jasser, I., A. Królicka \& A. Karnkowska-Ishikawa, 2011. A novel phylogenetic clade of picocyanobacteria from the
Mazurian lakes (Poland) reflects the early ontogeny of glacial lakes. FEMS Microbiology Ecology 75: 89-98.

Kallas, T. \& R. Castenholz, 1982. Rapid transient growth at low $\mathrm{pH}$ in the cyanobacterium Synechococcus sp. Journal of Bacteriology 149: 237-246.

Kurian, D., K. Phadwal \& P. Mäenpää, 2006. Proteomic characterization of acid stress response in Synechocystis sp. PCC 6803. Proteomics 6: 3614-3624.

Lu, Z., N. Jiao \& H. Zhang, 2006. Physiological changes in marine picocyanobacterial Synechococcus strains exposed to elevated $\mathrm{CO}_{2}$ partial pressure. Marine Biology Research 2: 424-430.

Malinsky-Rushansky, N. \& T. Berman, 1991. Picocyanobacteria and bacteria in lake Kinneret. International Revue der gesamten Hydrobiologie 76: 555-564.

Morán, X. A. G., Á. López-Urrutia, A. Calvo-Díaz \& W. K. W. $\mathrm{Li}, 2010$. Increasing importance of small phytoplankton in a warmer ocean. Global Change Biology 16: 1137-1144.

Partensky, F., J. Blanchot \& D. Vaulot, 1999. Differential distribution and ecology of Prochlorococcus and Synechococcus in oceanic waters: a review. Bulletin de l'Institut Océanographique (Monaco) 19: 457-475.

Raven, J. A., 1998. The twelfth Tansley lecture. Small is beautiful: the picophytoplankton. Functional Ecology 12: 503-513.

Richardson, T. L. \& G. A. Jackson, 2007. Small phytoplankton and carbon export from the surface ocean. Science 315 : 838-840.

Rodríguez, F., J. L. Oliver, A. Marin \& J. R. Medina, 1990. The general stochastic model of nucleotide substitution. Journal of Theoretical Biology 142: 485-501.

Sánchez-Baracaldo, P., B. A. Handley \& P. K. Hayes, 2008. Picocyanobacterial community structure of freshwater lakes and the Baltic Sea revealed by phylogenetic analyses and clade-specific quantitative PCR. Microbiology 154: 3347-3357.

Smith, S. W., R. Overbeek, C. R. Woese, W. Gilbert \& P. M. Gillevet, 1994. The genetic data environment: an expandable GUI for multiple sequence analysis. Computer Applications in the Biosciences 10: 671-675.

Søndergaard, M., 1991. Phototrophic picoplankton in temperate lakes: seasonal abundance and importance along a trophic gradient. International Review of Hydrobiology 76: 505-522.

Stanier, R. Y., R. Kunisawa, M. Mandel \& G. Cohen-Bazire, 1971. Purification and properties of unicellular blue-green algae (order Chroococcales). Bacteriological Reviews 35: 171-205.

Steinberg, C. E. W., H. Schafer \& W. Beisker, 1998. Do acidtolerant cyanobacteria exist? Acta Hydrochimica et Hydrobiologica 26: 13-19.

Stockner, J. G. \& K. S. Shortreed, 1991. Autotrophic picoplankton: community composition abundance and distribution across a gradient of oligotrophic British Columbia and Yukon Territory lakes. International Review of Hydrobiology 76: 581-601.

Thompson, J. D., T. J. Gibson, F. Plewniak, F. Jeanmougin \& D. G. Higgins, 1997. The ClustalX windows interface: flexible strategies for multiple sequence alignment aided by quality analysis tools. Nucleic Acids Research 24: 4876-4882.

Vörös, L., C. Callieri, K. V-Balogh \& R. Bertoni, 1998. Freshwater picocyanobacteria along a trophic gradient and light quality. Hydrobiologia 369(370): 117-125. 